\title{
MATERIALIEN
}

WIENER SLAVISTISCHES JAHRBUCH, Band 55/2009, 235-243

(C) 2009 by Österreichische Akademie der Wissenschaften, Wien

ROMAN MNICH

\section{Ivan Franko und Theodor Herzl: Über eine nicht stattgefundene Begegnung in Wien im Winter $1893^{1}$}

Bei der folgenden Fragestellung handelt es sich beinahe um eine Kriminalgeschichte, belehrend und bis heute zum Teil rätselhaft. Der bekannte ukrainische Wissenschaftler, Kulturschaffende und Politiker Vasyl' Ščurat (1871-1948) veröffentlichte 1937 in der polnischsprachigen jüdischen Zeitung „Chwila“ einen Auszug aus seinen Erinnerungen über Ivan Franko unter dem Titel Wówczas było to jeszcze mrzonk $q^{2}$, der im Original am Ende dieses Artikels angefügt ist. „Chwila. Dziennik poświęcony sprawom politycznym, społecznym i kulturalnym“ war eine jüdische Zeitung, die in Lemberg in polnischer Sprache von 10. Januar 1919 bis 7. September 1939 erschien $^{3}$.

${ }^{1}$ Dieser Text ist ein Teil der Forschungen aus dem Projekt „Ivan Franko und das Judentum“, durchgeführt in Rahmen des Projekts M1025-G03 (Lise-Meitner-Programm, Fonds zur Förderung der wissenschaftlichen Forschung, Wien).

${ }^{2}$ Vgl. Dr. Wassyl Szczurat, Wówczas byto to jeszcze mrzonkq, in: Chwila poranna, czwartek, 5 sierpnia 1937, 5. Es sei darauf hingewiesen, dass in der Monographie von Jaroslav Hrycak über Ivan Franko zweimal ein falscher Titel und ein falsches Datum der Veröffentlichung dieses Textes von Ščurat genannt wird (Wtedy było to jeszce wrzmięnkq statt Wówczas byto to jeszcze mrzonka, und statt 5. August - 5. Juli, vgl: Ярослав Грицак, Пророк у своїй вітчизні. Франко та його спільнота, Київ 2006, 525, 599). Die ukrainische Übersetzung der Erinnerungen von Ščurat aus dem Polnischen fertigte Andrij Skoc' an. Vgl. Андрій Скоць, Іван Франко і Теодор Герцель у споминах Василя Щурата, in: Українське літературознавство, Вип. 62: Іван Франко. Статті і матеріали, Львів 1996, 46-54.

3 Vgl. Barbara Łętocha, „Chwila“ gazeta Żydów lwowskich (http://www.lwow.home.pl/ rocznik/chwila.html). 
Auf diese Erinnerungen von Ščurat stützt sich bis heute der „Herzl-Diskurs“ in der Franko-Forschung, der verschiedene Aspekte hat, vom interessanten Faktum eines Treffens zwischen dem Klassiker der ukrainischen Literatur mit dem Begründer des Zionismus bis zur Interpretation von Frankos Poem Mojsej. Dabei ist zu beachten, dass Ščurats Erinnerungen sich auf die Deutung eben dieses Poems, das für Leben und Werk Frankos von besonderer Bedeutung ist, konzentrieren; Ščurat deutet die Begegnung Frankos mit Herzl in Wien im Februar 1893 als Anstoß für die Idee zum Poem Mojsej.

Eine ganze Reihe von Forschern hat auf diesen Erinnerungen ihre Interpretationen dieses Poems gegründet ${ }^{4}$, man leitete daraus die typologische Ähnlichkeit des ukrainischen Nationalismus bei Franko mit dem Zionismus Herzls ab ${ }^{5}$. Es mag paradox klingen, aber eine detaillierte Untersuchung dieser Frage erweist genau das Gegenteil: die Biographie Herzls kennt den Wien-Aufenthalt am Beginn des Jahres 1893, von dem Ščurat spricht, nicht. Von Oktober 1891 bis Juli 1896 lebte Herzl als Korrespondent der Wiener „Neuen Freien Presse“ in Paris ${ }^{6}$. Der Name Franko (so wie auch der von Ščurat) kommt in Herzls Tagebuch überhaupt nicht vor ${ }^{7}$, obwohl Ščurat schreibt, dass Herzl ,schon lange den großen Wunsch gehegt hatte, Franko kennenzulernen“. Ebenso wenig lassen sich auch andere Angaben aus Ščurats Erinnerungen bestätigen: Friedrich Samuel Krauss gehörte nicht zu den guten Bekannten Herzls; auch konnte Franko 1893 noch nicht offen seine Ideen einer nationalen und territorialen Unabhängigkeit der Ukraine deklarieren, weil er sich zu diesem Zeitpunkt unter dem gewichtigen Einfluss der sozialen Ideen von Mychajlo Drahomanov befand und seine eigene nationale Konzeption noch nicht entwickelt hatte.

Außer diesen Erinnerungen von Vasyl' Ščurat gibt es keine Dokumente (Memoiren, Tagebücher, Briefe, Publikationen), welche die Begegnung Ivan Frankos mit Theodor Herzl belegen könnten. Deshalb bin ich der Meinung, dass eine solche Begegnung nie stattgefunden, dass vielmehr Ščurat die ganze Geschichte erfunden hat. Warum er das getan hat, ist eine andere Frage.

Versuchen wir nun alle Gründe „für“ und „gegen“ eine Begegnung von Ivan Franko und Theodor Herzl in Wien im Februar 1893 im Detail darzustellen. Wenn

${ }^{4}$ Als erster schrieb darüber Andrij Skoc', vgl. А. Скоць, До генези поеми I. Франка „Мойсей“, в: Іван Франко. Статті і матеріали, Вип. 12, Львів 1965, 59-60. Aber die ukrainische Forschung bezieht sich in der Regel auf die englischsprachige Publikation von A. Wilcher, in der der Autor den Originaltext von Ščurat mit einer Übersetzung ins Englische sowie der Rezension Frankos auf das Buch von Thodor Herzl Der Judenstaat. Versuch einer Lösung der Judenfrage abdruckte (Asher Wilcher, Ivan Franko and Theodor Herzl: To the Genesis of Franko's Mojsej, in: Harvard Ukrainian Studies, Volume VI. Number 2, June 1982 [Cambridge], 233-243).

5 Оксана Забужко, Філософія української ідеї та європейський контекст, Київ 1993 (passim).

6 Alex Bien, Theodor Herzl. A Biographie, London 1956, 72-121.

7 Vgl. Theodor Herzl, Briefe und Tagebücher. Erster Band. Briefe und autobiographische Notizen 1866-1895. Bearbeitet von Johannes Wachten, Darmstadt 1983. 
es um die Gründe dafür geht, so gibt es nur ein Argument - die erwähnten Erinnerungen von Ščurat. Bislang gibt es, wie bereits erwähnt, kein anderes Dokument, das diese Tatsache bestätigen könnte.

Alle vorhandenen Fakten und Argumente sprechen gegen eine solche Begegnung, angefangen von dem Umstand, dass Theodor Herzl im Winter 1892 nicht in Wien war. Er weilte, wie schon erwähnt, mit seiner Familie als Korrespondent der „Neuen Freien Presse“ in Paris. Man kann natürlich vermuten, dass Herzl dienstlich für ein paar Tage nach Wien gekommen sei, aber ein solcher Aufenthalt wäre wohl in irgend einer Weise in Herzls Biographie, die ziemlich gründlich erforscht ist, oder in seinen Briefen und Tagebüchern festgehalten.

Weiters unterhielt Theodor Herzl keine freundschaftlichen Beziehungen zu dem bekannten Volkskundler und Herausgeber der Zeitschrift „Am Ur-Quell“, Friedrich Salomon Krauss, woran sich Ščurat angeblich „,erinnern“ kann. Unter den engen Bekannten Herzls scheint Krauss nicht auf ${ }^{8}$, wie sich auch umgekehrt der Name Herzl nicht unter den Bekannten von Krauss findet ${ }^{9}$. Darüberhinaus sympathisierte Krauss nie mit zionistischen Ideen, lehnte den Zionismus als solchen ab und geriet als Sekretär der Organisation „Israelitische Allianz zu Wien“ zusammen mit deren Begründer, Baron Moritz Hirsch (1831-1896), 1895 in einen eigenartigen Konflikt mit Theodor Herzl. Diesen Konflikt mit der „Israelitischen Allianz zu Wien“ nach einem Treffen Herzls mit Hirsch erwähnt Herzl selbst in seinem Zionistischen Tagebuch. Moritz Hirsch hatte kein Verständnis für die zionistischen Ideen Herzls und verweigerte ihnen finanzielle Unterstützung. Nirgendwo in seinen Briefen und Tagebüchern erwähnt Herzl den Namen Friedrich Salomon Krauss - die beiden haben sich aller Wahrscheinlichkeit nach überhaupt nie getroffen. Einmal mehr scheinen Ščurats Erinnerungen daran, dass die Beiden Freunde waren, eine Erfindung zu sein.

Hier ist noch darauf hinzuweisen, dass Krauss nicht nur keine Sympathien für zionistische Ideen hegte, sondern den Zionismus kategorisch ablehnte und als eigenartigen „Sport“ für diejenigen Juden (er nennt sie „Auchjuden“) bezeichnete, die das Judentum nie verstanden hätten und auf dieses Nichtwissen auch noch stolz wären. Gerade deshalb trat er für die totale Assimilierung der Juden ein und konnte verständlicherweise niemals mit Theodor Herzl Gespräche über die Schaffung eines unabhängigen jüdischen Staates führen, auch wenn eine Begegnung zwischen den beiden stattgefunden hätte ${ }^{10}$.

${ }^{8}$ Vgl. den Kreis der Bekannten nach dem Artikel über Theodor Herzl, in: Lexikon deutschjüdischer Autoren. Band 11: Hein - Hirs, München 2002, 215.

9 Vgl. den Kreis der Bekannten nach dem Artikel über Friedrich Salomon Krauss in: Lexikon deutsch-jüdischer Autoren. Band 14: Kest - Kulk, München 2006, 339.

10 Vgl.: „Wie viele seiner Wiener Glaubensgenossen um die Jahrhundertwende strebte Krauss nach gesellschaftlicher Anerkennung und totaler Assimilation. Zionismus in Form einer radikaler Betonung kultureller Unterschiede lehnte er schärfstens ab: „Der Zionismus ist förmlich ein Sport von Auchjuden, die niemals im religiösen Judentum Bescheid 
In diesem Zusammenhang ist es von großer Wichtigkeit zu betonen, dass Theodor Herzl selbst im Jahr 1893 noch keinerlei zionistische Ideen entwickelt hatte. Er vertrat teilweise eine liberale Assimilation und sprach sich sogar für eine Taufe der Juden aus ${ }^{11}$. Erst der bekannte Prozess gegen Alfred Dreyfuss, der am 15. Oktober 1894 verhaftet worden war, führte zu einer Änderung in Herzls Weltanschauung und ließ seine Konzeption eines jüdischen Staates reifen. Ein Meilenstein in diesem Kontext ist das Erscheinen seines Buches Der Judenstaat am 14. Februar 1896 in Wien. Deshalb konnte Herzl weder im Februar 1893 noch später (bis Anfang 1895) etwas zur Gründung eines jüdischen Staates sagen, weil er zu dieser Zeit noch ganz andere Überzeugungen vertrat. Unter diesem Aspekt sind Ščurats Erinnerungen also keine Erinnerungen, sondern Erfindung.

Vasyl' Ščurat erwähnt auch seine eigenen späteren, häufigen Treffen mit Theodor Herzl in Wien, bei denen Herzl immer gefragt habe, was denn Franko mache. Keines von diesen ,häufigen“ Treffen scheint in Herzls Tagebuch auf. Der Name Ščurat kommt in Herzls Briefen und in seinem Tagebuch überhaupt nicht vor. Wenn man die vielfältigen Verpflichtungen Herzls und sein Engagement in der zionistischen Bewegung nach 1896 berücksichtigt, seine extrem häufigen Reisen und die verschiedensten Begegnungen, so scheinen Gespräche mit Ščurat zum Thema, was Franko denn mache, äußerst unrealistisch.

Es ist auch interessant, dass weder Theodor Herzl noch Friedrich Salomon Krauss oder Vasyl' Ščurat selbst in der einschlägigen Forschung als Stammgäste des Café Central in Wien gelten ${ }^{12}$. Herzl hingegen schreibt, dass er 1897-1899 oft ein anderes Wiener Café - das Café Louvre - besucht hätte, weil sich dort jeden Donnerstag die Wiener Zionisten getroffen hätten ${ }^{13}$. Dieses Café befindet sich in der Wipplingerstraße, d. h. in derselben Straße, wo Ivan Franko und Vasyl' Ščurat 1892/93 wohnten, als Franko an seiner Dissertation arbeitete. Da Ščurat später häufig in Wien war, ist es gut möglich, dass er Theodor Herzl zufällig auf der Straße, neben dem Café Louvre, gesehen haben könnte. Das ist heute wohl die einzige Erklärung für diese erfundenen Erinnerungen an Theodor Herzl.

Weiter sei darauf hingewiesen, dass auch die Texte von Ivan Franko gewichtige Argumente für diese ,nicht stattgefundene Begegnung“ mit Theodor Herzl enthalten. Hier sind es vor allem drei Aspekte, die Aufmerksamkeit verdienen. Erstens

wussten und die mit ihrer Unwissenheit prunkten“. Zit. nach: Raymond L. Burt, Friedrich Salomo Krauss (1859-1938), Wien 1990, 74.

11 Vgl.: „Darum müsste man die Judenbuben taufen, so lang sie unzurechnungsfähig sind, so dass sie nichts dafür und nichts dagegen könnten. Untertauchen im Volk! “ Zit. nach: Lexikon deutsch-jüdischer Autoren. Band 11. Hein - Hirs, München 2002, 217.

12 Andrea Portenkirchner, Die Einsamkeit am „Fensterplatz“ zur Welt. Das literarische Kaffeehaus in Wien 1850-1950, in: Michael Rössner (Hrsg.), Literarische Kaffeehäuser Kaffeehausliteraten, Wien 1999, 31-65.

13 Theodor Herzl, Briefe und Tagebücher. Zweiter Band. Zionistisches Tagebuch 18951899. Bearbeitet von Johannes Wachten und Chaya Harel, Darmstadt 1983, 438. 
hatte Franko während seines Aufenthalts in Wien im Winter 1892/93 ziemlich ausführlich über seine Aktivitäten, Begegnungen und andere Ereignisse an Mychajlo Drahomanov berichtet. In keinem der bekannten Briefe Frankos an Drahomanov ist die Rede von einem Treffen mit Herzl, es fällt nicht einmal dessen Name.

Zweitens wäre laut Ščurats Erinnerungen Franko schon 1893 den zionistischen Ideen stark zugeneigt gewesen, der Idee der Erschaffung eines jüdischen Staates. In diesen Erinnerungen sagt Franko zu Herzl: „Bardzo mi się podobała pańska IDEA ODBUDOWANIA PAŃSTWA ŻYDOWSKIEGO - odezwał się Franko. - Bardzo mnie zainteresowała, ponieważ jest jakby SIOSTRĄ RODZONĄ NASZEJ UKRAIŃSKIEJ IDEI ODBUDOWANIA PAŃSTWA UKRAIŃSKIEGO. Ale czy jedna jak i druga są dzisiaj ziszczalne?" Wenn man aber einen Blick auf Frankos im selben Jahre 1893 veröffentlichten Text $\dot{Z} y d z i$ o kwestji $\dot{z} y d o w s k i e j{ }^{14}$ wirft, sieht man, dass die Ideen, die Franko um diese Zeit äußert, nichts mit dem gemein haben, woran sich Ščurat erinnert.

Dort schreibt Franko:

Powiem wyraźniej: jeżeli kierunek ten wogóle szkodliwym jest dla kraju - nie dla tego że jest narodowym żydowskim, lecz dla tego że jest wstecznym i antycywilizacyjnym, to dla samych że Żydów galicyjskich może mieć skutki wprost fatalne. Raz nie zapominajmy, jakie muszą być praktyczne wyniki agitacji sionistycznej. Odwracając masy żydowskie od zdobyczy cywilizacji, od postępu ku ciemnym labiryntom talmudu, syoniści spotęgują własnie te przymioty Żydów, które dziś czynią ich głównie niemiłymi i szkodliwymi społeczeństwom europejskim, a więc zamiast rozwiązania kwestji żydowskiej doprowadzą tylko do jej zaostrzenia, przyśpieszą może nieprzewidzialne katastrofy. Że ich plany o państwie żydowskim w Palestynie są dzi ec innemi mrzon ka mi, tego nawet dowodzić nie potrzeba. A w takim razie czyż syonizm nie jest grą bardzo niebezpieczną, a już wcale nie niewinną utopją? Potępiając stanowczo syonizm, nie myślę przez to wcale potępiać narodowego ruchu żydowskiego w zasadzie ${ }^{15}$ (Hervorhebung von R. M.).

In diesem Zitat lässt das Wort „mrzonka“ aufhorchen, das im Text von Ščurat zum Schlüsselwort wird. Es scheint also nicht der Fall zu sein, dass dieses Wort aus dem Epigraph zu Herzls Buch stammt, wie manche Forscher annehmen - so der bereits zitierte Asher Wilcher ${ }^{16}$. Ščurat könnte das Wort „mrzonka“ (im Sinn eines bestimmten Konzepts) aus eben diesem Artikel von Franko in eben diesem Jahr 1893, das Ščurat in seinen Erinnerungen beschreibt, übernommen haben.

Schließlich ist noch ein wichtiger Aspekt zu berücksichtigen - die Genesis des Poems Mojsej, die Ščurat mit der Begegnung Frankos und Herzls in Verbindung bringt. Wichtige Hinweise auf die Entstehung des Poems finden sich in den beiden

${ }^{14}$ Iwan Franko, Żydzi o kwestji żydowskiej, w: Tydzień (dodatek literacki do Kurjera Lwowskiego), 1893, Nr. 2-8, 10-14.

15 Iwan Franko, Żydzi o kwestji żydowskiej, w: Tydzień (dodatek literacki do Kurjera Lwowskiego), 1893, Nr. 10, 94.

16 Asher Wilcher, Ivan Franko and Theodor Herzl: To the Genesis of Franko's Mojsej, in: Harvard Ukrainian Studies. Volume VI. Number 2, June 1982 (Cambridge), 234. 
Vorworten des Verfassers - dem polnischen ${ }^{17}$ und dem ukrainischen ${ }^{18}$, wo Franko ziemlich ausführlich über die Quellen dieses Werks berichtet. Vor allem im ukrainischen Vorwort betont er, dass „bei der häufig gestellten Frage nach den Quellen dieses Poems niemand von den ruthenischen Intellektuellen die eigentlichen und vom Inhalt vorgegebenen Quellen beachtet, und fast ein jeder, wie ich das im Weiteren zeigen werde, diese irgendwo anders, in der Regel dort gesucht hat, woher ich nichts genommen habe“. Und weiter: „Mein Poem beruht fast zur Gänze auf biblischen Themen“. Besondere Beachtung verdient Frankos Bekenntnis, dass „ich den Tod des Moses als von seinem Volke nicht anerkannten Proph e ten zum zentralen Thema meines Poems gemacht habe ${ }^{\text {"19 }}$ (Hervorhebung von R. M.). Theodor Herzl konnte man 1905 keinesfalls als „,nicht anerkannten“ Propheten bezeichnen, er war eher im Gegenteil die allgemein anerkannte führende Persönlichkeit der zionistischen Bewegung. Seltsam mutet in diesem Kontext die Hypothese von der Nähe der Figur des Moses zur Person Herzls an, so wie auch die Interpretation eines anderen Umstands aus der Fabel. Nicht Moses, sondern der Dämon Asa$\mathrm{sel}^{20}$ weist in Frankos Poem auf Palästina als das den Juden von Gott verheißene Land. Wenn man bedenkt, dass Theodor Herzl die letzten Jahre seines Lebens damit verbrachte, die Rückkehr der Juden nach Palästina und die Schaffung eines eigenen Staates ebendort zu begründen, dann kann es also keinerlei Parallen zwischen der Gestalt des Moses und der Person Theodor Herzls geben.

Es ist klar, dass Herzls Name in Frankos Vorworten zum Poem Mojsej nie fällt, obwohl sich zu dieser Zeit Frankos Ansichten, was die Bildung eines unabhängigen ukrainischen Staates betrifft, mit der zionistischen Konzeption der Schaffung eines unabhängigen jüdischen Staates eindeutig deckten. Wenn Franko tatsächlich eine Begegnung mit Herzl gehabt hätte und das irgendwie mit dem Poem Mojsej in Verbindung zu bringen gewesen wäre, so hätte Franko dies wohl erwähnt (über ein Treffen mit Tomáš Masaryk, einem anderen politischen Führer, hat Franko in seinen Erinnerungen berichtet ${ }^{21}$ ). Wozu schließlich soll man die Ursachen für die Entstehung des Poems Mojsej außerhalb jenes Kontexts suchen, den Ivan Franko selbst betont hat?

${ }^{17}$ Vgl.: Przedmowa, in: Iwan Franko, Mojżesz. Poemat. Tłómaczył z ukraińskiego przy współdziale autora Włodzimierz Kobryn, Lwów 1913, III-XXIII.

18 Vgl.: Передмова, in: Іван Франко, Мойсей. Поема. Друге виданнє 3 передмовою, Львів 1913, III-XVII.

19 ibidem, III.

20 Im ukrainischen Vorwort wird dieser Umstand von Franko besonders betont: „In der biblischen Erzählung zeigt Gott selbst dem Moses Palästina, in meinem Poem übertrage ich diese Rolle dem Asasel mit der Absicht, so stark wie nur möglich den Kontrast zwischen den prophetischen Versprechungen und dem, was die Juden in Palästina wirklich erwartete, zu zeigen" (XI).

21 Vgl.: Ivan Franko, Moji znosyny z prof. Masarykom, in: T. G. Masarykovi k šedesátým narozeninám. Grosman a svoboda v Praze 1911, 16-18. 
Die hier angeführten Bemerkungen zeugen in erster Linie davon, wie sehr die Franko-Forschung auch heute noch kompliziert und kontroversiell gehalten ist und wie sehr sie einer wissenschaftlichen statt einer „hurrapatriotischen“ Einstellung bedarf.

Zusatz: Text der Erinnerungen von Vasyl' Ščurat, aus: „Chwila poranna“, Donnerstag, 5. August 1937

\section{Dr Wasyl Szczurat}

Wówczas byto to jeszcze mrzonkq ...

Lat temu będzie już czterdzieści i pięć, kiedy zamierzając poświęcić się studiom slawistyki, razem z Iwanem Franka, wybrałem się do Wiednia. - Franko w swych studiach - po przerwie prawie piętnastoletniej - wtedy był już na ukończeniu, kiedy ja je dopiero rozpoczynałem. Zamieszkawszy we wspólnym pokoiku przy Wipplingerstrasse, razem bywaliśmy na wykładach uniwersyteckich, razem chadzaliśmy po restauracjach na obiady, razem też nałogowo odwiedzaliśmy dzień po dniu kawiarnię „Centralną” przy Herrengasse. Tam przy czarnej kawie czytywało się co najmniej po tuzin świeżych dzienników, o ile ktoś trzeci z miejsca temu nie przeszkodził. A bywał tym trzecim zazwyczaj ktoś ze znajomych Franki, rzadko z moich, bo u mnie jeszcze wielu ich nie było, zwłaszcza takich, z którymi dłuższa rozmowa mogłaby dla Franki przedstawić jakiś większy interes. Niebawem przecież nadarzyła mi się sposobność zbliżenia do niego osoby, o której już słyszał wiele takiego, co mogłoby być dlań sensacja.

Było to prawdopodobnie w lutym 1893 roku. Wyszedłszy z seminarium profesora Jagieła, wstępujemy z Franką do „Centralnej”, gdzie miał nas oczekiwać dr Monat, kolega szkolny Franki z gimnazjum drohobyckiego. Zamiast niego zastajemy przy zajmowanym przez nas codziennie stole doktora Fryderyka Samuela Kraussa, który będąc sekretarzem „Israelitische Alliance” był równocześnie wydawcą i redaktorem miesięcznika folklorystycznego „Am Urquell”. Poznawszy się z nim przed jakimi dwoma miesiącami, mogliśmy się przysiąść do niego, gdyby nie to, że siedział już w towarzystwie nieznanego nam człowieka. Przeto witamy go tylko ukłonem i zajmujemy miejsca przy stoliku sąsiednim.

- Ależ, panowie, prosimy do nas! - mówi natychmiast, ku nam przyskoczywszy dr Krauss i przedstawia nam swego towarzysza. BYŁ NIM TEODOR HERZL.

- Cieszy mnie bardzo, że pana poznaję - odezwał się Herzl do FRANKI - bo już parę razy wspominał mi o panu mój kolega. Mało powiedzieć: wspominał. Naopowiadał mi tyle, że poznać pana osobiście stało się moim najgorętszym życzeniem.

Tu muszę zauważyć, że poznawszy się z Kraussem, na jego własną prośbę byłem u niego z Franką już w grudniu 1892 roku. I już wówczas była tam mowa także o Herzlu. Szczegółów jej dzisiaj sobie dobrze nie przypominam; to jedno pamiętam, że wątkiem była idea sprecyzowana przez Herzla cztery lata później w monumentalnym dziele jego pod tytułem ,JUDENSTAAT". Ona też stała się tematem pierwszej rozmowy Franki z Herzlem po obopólnym wymienieniu kilku zdań konwencjonalnych.

- Bardzo mi się podobała pańska IDEA ODBUDOWANIA PAŃSTWA ŻYDOWSKIEGO - odezwał się Franko. - Bardzo mnie zainteresowała, ponieważ jest jakby SIOSTRA RODZONĄ NASZEJ UKRAIŃSKIEJ IDEI ODBUDOWANIA PAŃSTWA UKRAIŃSKIEGO. Ale czy jedna jak i druga są dzisiaj ziszczalne?

- Czemu by nie miało być? - odpowiedział Herzl - wszystko może mieć miejsce w świecie, co się tylko zmieści w ludzkiej głowie.

- W rozumnej głowie! - dodał Franko.

- Tak jest, w rozumnej głowie, bo o takiej tylko warto mówić ludziom, którzy chcą uchodzić za rozumnych - mówił Herzl.

W głowie rozumnej czy rozsądnej zrodzona chociażby najszczytniejsza idea będzie ziszczalną, jak tylko wznieci zapał w najszerszych masach narodu i wydźwignie $\mathrm{z}$ łona ich obrońców swoich gotowych chociażby na męczeństwo. Jeśli nam ongiś udało się dzięki Mojżeszo- 
wi zrzucić z siebie jarzmo egipskie i odzyskać Palestynę, czemu by dzisiaj miało to być niemożliwym?

- Ongiś - zauważył Franko - mieliście Mojżesza i tylko jedno jarzmo egipskie do zrzucenia. A dzisiaj? My, Ukraińcy, mamy ich trzy, a wy chyba dziesięć razy więcej, boście po całym świecie rozsiani.

- Mojżeszowie nie rodzą się co dnia, to prawda; oni się kształtują pod naciskiem zewnętrznym - odparł Herzl - a ten ucisk zewnętrzny u nas jest dziesięciokroć większy niż u was. Jeśli wy kiedyś go tak odczujecie jak my, to i u was zaczną się oglądać za swoim Mojżeszem i pewnie znajdą go, chociaż dzisiaj może jeszcze by go ukamienowali. Zresztą czas może wszystko przyspieszyć.

- Tu przyznaję panu zupełną rację - zgodził się po krótkim milczeniu Franko i uścisnął Herzlowi serdecznie rękę.

Co myślał sobie Herzl, mówiąc, że czas może wszystko przyspieszyć, z tego nie zdawałem sobie sprawy; później Franko powiedział mi, że to przyspieszyć może zmiana konstelacji politycznej w Europie. Skutków wielkiej wojny on jeszcze nie przewidywał, bo i samej wojny się nie spodziewał.

Niestety w notatkach moich $\mathrm{z}$ tych dawnych czasów nie znalazłem więcej wzmianek o stosunku Franki do Herzla. To tylko dodać mogę, że Herzl, ile razy z nim spotkałem się, zawsze zapytywał mnie, czym się Franko zajmuje. Informując go o dawniejszych pracach Franki z zakresu kwestii semickiej, mogłem podawać mu tylko wiadomości powierzchowne. Teraz, kiedy w Kijowie prof. P. Kurdjawcew dał nam specjalne studium na ten temat ${ }^{*}$, mogłoby ono wyglądać inaczej. Ale nawet tak sumiennemu badaczowi, jakim okazał się prof. Kurdjawcew przyśnić się nie mogło, że pomysł najwybitniejszego poematu Franki pod tytułem „Mojżesz” wyłonił się ze streszczonej powyżej rozmowy autora z Herzlem. Z pomysłem tym nosił się Franko długo, bardzo długo. Już w roku 1893 w Wiedniu kreślił szkic poematu, usiłując przedstawić żydowskiego Mojżesza tak, ażeby czytelnik ukraiński mógł poznać w nim losy wodza ukraińskiego. Kiedy mu pierwsze próby nie udawały się, rzucił je do kosza. Dopiero po latach, po gorzkich przeżyciach osobistych, które doprowadziły go do znanych nam konfliktów tak ze społeczeństwem ukraińskim, jak z polskim, odczuł silniej

\section{TRAGEDIĘ ŻYCIOWĄ WODZA ŻYDOWSKIEGO}

i dał nam poemat tylko na pozór historyczny, bo pełny aktualności z punktu widzenia losów wodza ukraińskiego narodu. Stało się to w roku 1905,

\section{KTO WIE, CZY I NIE W ZWIĄZKU Z WRAŻENIEM WYWOŁANYM ZGONEM HERZLA ...}

To, co o genezie poematu Franki powiedziałem zgadzałoby się też z faktem, że w rok później zaczął Franko spisywać wspomnienia swoje o Żydach, z którymi utrzymywał bliższe stosunki przyjacielskie. Niestety doprowadził je tylko do czasu wstapienia swego na Uniwersytet Lwowski i te pozostały po nim w rękopisie, z którego na światło dzienne wydobył je dopiero przed rokiem I. Wozniak ${ }^{* *}$. - Wielka szkoda, że tych ciekawych wspomnień nie dociągnął Franko bodaj do czasu poznania się z autorem ,Judenstaat'u”.

A b stract: Ivan Franko and Theodor Herzl: On a meeting in Vienna in the winter of 1893 that never took place. The article presents a 'deconstruction' of a traditional story in Ukrainian literary criticism about the encounter of Ivan Franko, a famous Ukrainian writer and essayist, with Theodor Herzl, the founder of Zionism, in Vienna in the winter of 1893.

* Prof. P. Kudrjawcew, Jewrejstwo, jewreji ta jewrejska sprawa w tworach Iwana Franka, ** (Zbirnyk prać jewr. istor.-archeograf. Komisji, t. II, Kijów 1929).

** Iwan Franko: „Moji znajomi żydy” („Diło” 1936, Nr. 117-119). 
Evidence of this encounter was proffered in the memoirs of Wasyl Szczurat (1871-1948), a Ukrainian writer and public figure. The author challenges the fact of the encounter, stating that Szczurat's memoirs were faked and Ivan Franko never met Theodor Herzl. The article provides the original text of Szczurat's memoirs and gives an in-depth commentary on the story/episode of a non-encounter.

K e y w o r d s : Ivan Franko, Theodor Herzl, Wasyl Szczurat, Vienna, Zionism

Roman Mnich

Akademia Podlaska, Wydział Nauk Humanistycznych

Instytut Filologii Polskiej

ul. G. Orlicz-Dreszera 19/21, paw. A

08-110 Siedlce, Polen

mnichrw@yahoo.de 
